\title{
Distribuição espacial do banco de sementes de plantas daninhas em área de monocultura de feijão
}

\author{
Diego Stähelin \\ Mario Alvaro Aloisio Verissimo \\ Pedro Patric Pinho Morais \\ Marlon Mathias Dacal Coan \\ Jefferson Luis Meirelles Coimbra \\ Altamir Frederico Guidolin* \\ Departamento de Agronomia, Instituto de Melhoramento e Genética Molecular da UDESC (IMEGEM), \\ PPG em Produção Vegetal, Universidade do Estado de Santa Catarina \\ Av. Camões 2090, CEP 88520-000, Lages - SC, Brasil \\ *Autor para correspondência \\ a2afg@cav.udesc.br
}

\section{Resumo}

O presente trabalho tem por objetivo conhecer as características de distribuição espacial do banco de sementes de plantas daninhas visando o auxilio na tomada de decisão na adoção de técnicas de manejo, em uma área sob monocultivo de feijão. Para tanto foram utilizadas ferramentas de agricultura de precisão bem como técnicas de análise geoestatística. Os dados foram obtidos através da coleta de amostras de solo em 24 pontos georreferenciados dentro de uma malha quadrangular com espaçamento de 20x20 metros. As amostras de solo foram acondicionadas em bandejas plásticas dando-se as condições ideais para a germinação das sementes. Os dados obtidos revelaram pontos com infestações potenciais de cerca de 8000 plantas $\mathrm{m}^{-2}$ constituindo importante problema por competirem por recursos do ambiente com o feijão, desfavorecendo seu desenvolvimento e consequentemente a produção de grãos.

Unitermos: agricultura de precisão, aplicação localizada de defensivos, variabilidade espacial

\section{Abstract}

Space distribution of a weed seedbank in a bean cultivation area. The objective of this work was to elucidate the characteristics of space distribution of a weed seedbank in order to assist in decision-making for the adoption of management techniques applied to an area under bean monoculture. Agricultural precision tools, as well as techniques of geostatistic analysis, were utilized. The samples were composed of 24 soil samples from georeferenced points, within a quadratic mesh consisting of $20 \times 20$ meter cells. The samples of soil were conditioned in plastic trays to provide ideal conditions for seed germination. Some samples presented a potential weed infestation of about 8000 plants $\mathrm{m}^{-2}$ constituting a problem for bean cultivation, disfavoring its development and grain yield.

Key words: patch spraying, precision agriculture, spatial variability 


\section{Introdução}

O banco de sementes é uma reserva de sementes viáveis no solo. A variabilidade e densidade de espécies de um povoamento de sementes no solo, em um dado momento, são o resultado do balanço entre entrada de novas sementes e perdas por germinação, deterioração, parasitismo, predação e transporte (Carmona, 1992).

De acordo com Miranda (1999) a agricultura de precisão tem como fundamento a obtenção de um conhecimento espacial preciso da atividade agrícola, envolvendo processos complexos, frequentemente baseados no uso de dados obtidos com auxílio de satélites. Neste sentido a agricultura de precisão acaba por tornar-se uma filosofia de gerenciamento agrícola que parte de informações precisas e se completa com decisões exatas (Roza, 2000).

Com a utilização de técnicas e ferramentas disponíveis na agricultura de precisão, como a utilização do georreferenciamento, torna-se possível realizar o mapeamento de diversas variáveis. Dentre elas o mapeamento das plantas daninhas merece especial atenção. Economias da ordem de $72 \%$ do volume de herbicidas aplicados em áreas agrícolas já foram obtidas na Europa em lavouras de soja quando aplicações localizadas de herbicidas foram feitas com base no mapeamento das plantas daninhas em comparação com aplicações convencionais em área total (Christensen et al., 1999)

A partir destas informações ambientais pode-se inferir qual o nível de risco de infestações que interferem na produção agrícola. Estudos e levantamentos de populações de plantas daninhas em ambientes agrícolas, além de permitirem a identificação da flora infestante e sua evolução numa área, podem ter aplicação na previsão de infestantes em culturas agrícolas (Voll et al., 1997).

Segundo Salvador e Antuniassi (2002), na aplicação localizada de herbicidas com uso de mapas, a identificação e posição das plantas daninhas são levantadas para elaboração de um mapa em uma primeira operação e a aplicação de herbicida sobre a área de interesse é realizada de acordo com os mapas gerados em uma segunda operação.
Existem diversos métodos de mapeamento das plantas daninhas presentes em uma área para levantamento de sua posição e características da infestação (Stafford e Miller, 1996; Clay e Johnson, 1999; Lamb e Brown, 2001), entre elas está a amostragem em grades ou malha de pontos pelo caminhamento no campo.

O objetivo deste trabalho foi fazer um levantamento da distribuição espacial do banco potencial de sementes de ervas daninhas presente na área experimental do Centro de Ciências Agroveterinárias da UDESC sob monocultivo de feijão.

\section{Material e Métodos}

A coleta de solo para o experimento foi realizada na área experimental do Centro de Ciências Agroveterinárias da UDESC, no município de Lages, localizado no Planalto Sul do Estado de Santa Catarina. O solo da área experimental é classificado como Cambissolo Húmico (Embrapa, 1999), apresentando as seguintes características: $40 \%$ de argila; $\mathrm{pH}$ em água 5,6 e pH SMP 6,2; 3,2mg.dm ${ }^{-3} \mathrm{de}$ P; $62 \mathrm{mg} \cdot \mathrm{dm}^{-3}$ de K; $3,9 \%$ de $\mathrm{MO} ; 5 \mathrm{cmol}_{\mathrm{c}} \cdot \mathrm{dm}^{-3} \mathrm{de} \mathrm{Ca}$; e $2,8 \mathrm{cmol}_{\mathrm{c}} \cdot \mathrm{dm}^{-3} \mathrm{de} \mathrm{Mg}$.

O controle de ervas daninhas na área vem sendo realizada com a utilização de inibidores da divisão celular (Metolachlor) em pré emergência e herbicidas inibidores da síntese de ácidos graxos (Setoxidim e Fluazifop-p-butil) e inibidores da enzima protoporfirinogêniooxidase (PROTOX), a qual atua na oxidação de protoporfirinogênio à protoporfirina IX (precursores da clorofila) (Fomesafen) em pós emergência da cultura. Cabe ressaltar que as coletas de solo foram realizadas durante o inverno. Desta forma, possíveis resíduos dos herbicidas aplicados no verão já haviam sido complexados pelos minerais de argila e matéria orgânica presentes no solo (Burgard et al., 1993; Weber et al.,1993; Cobucci, 1996; Keller et al., 1998) com a posterior degradação destes pela microfauna edáfica (Braverman et al., 1986; Harper, 1994; Zablotowicz et al., 2000), ou então lixiviados (Rodrigues e Almeida, 1998), não interferindo nas taxas de germinação das sementes avaliadas no presente estudo.

As coordenadas do perímetro da área e do ponto central das parcelas de amostragem foram determinadas 
com equipamento de sistema de posicionamento global, Leica ${ }^{\circledR}$ modelo SR20. Foram amostrados 24 pontos distribuídos em grade de $20 \times 20 \mathrm{~m}$. Para cada ponto georreferenciado foram coletadas $5 \mathrm{sub}$ amostras de 0 a $15 \mathrm{~cm}$ de profundidade, em forma de cruz dentro de um quadro amostral de 1 metro quadrado, utilizando-se um trado calador de $3,14 \mathrm{~cm}$ de diâmetro, perfazendo um total de 120 amostras (24 pontos x 5 sub amostras por ponto).

Para verificar a germinação do banco de sementes seguiu-se a metodologia proposta por Monquero et al. (2008), onde as amostras de solo coletadas na área experimental foram acondicionadas separadamente em bandejas plásticas com $1 \mathrm{~cm}$ de profundidade, em casa de vegetação. Durante todo o período de avaliação foram fornecidas condições ideais para a germinação das sementes, com temperatura e umidade relativa do ar controladas, além de irrigações sempre que necessário.

Após cada fluxo de emergência, as plantas foram identificadas com auxilio de chaves botânicas para as famílias infestantes (Kissmann, 1997; 2000; Kissmann e Groth, 1999), contadas e retiradas das bandejas. Aos 45 dias após a instalação do experimento em casa de vegetação, foi realizado um novo revolvimento do solo, para estimular novos fluxos de emergência. A quantificação das plântulas foi realizada até 90 dias depois da instalação do experimento. Na confecção dos mapas de distribuição espacial foram utilizadas as plantas daninhas de maior ocorrência na área experimental.
Os dados obtidos foram analisados e interpoladas pelo método da Krigagem (Imai et al., 2003), afim de se obter os mapas com suas respectivas curvas de infestação. A área amostrada está apresentada por coordenadas UTM (Universal Transverse Mercator) pertencentes ao fuso J 22 .

\section{Resultados e Discussão}

As espécies presentes na área em estudo, consideradas plantas daninhas por ocorrerem no mesmo período de crescimento do feijão, competindo com esta cultura por recursos do meio, podem ser visualizadas na Tabela 1. Nota-se a predominância de espécies pertencentes às famílias Poaceae e Asteraceae.

Os mapas de distribuição do banco de sementes foram subdivididos em Monocotiledôneas e Dicotiledôneas e dentro destas foi realizada a interpolação para as espécies mais representativas. As populações de plantas estão apresentadas nos gráficos em $0,15 \mathrm{~m}^{3}\left(1 \mathrm{~m}^{2}\right.$ de área $\mathrm{x}$ $0,15 \mathrm{~m}$ de profundidade).

A Figura 1 apresenta a distribuição espacial da população potencial total de ervas daninhas na área em estudo. Verifica-se a presença de pontos com populações potenciais de até 8000 plantas $\mathrm{m}^{-2}$ (áreas claras e picos) e populações potenciais mínimas de 517 plantas $\mathrm{m}^{-2}$ (áreas escuras e vales).

TABELA 1: Espécies de ervas daninhas emergidas em amostras de solo da camada de 0 a $15 \mathrm{~cm}$ de profundidade, provenientes da área de monocultivo de feijão. Lages, 2008.

\begin{tabular}{ccc}
\hline Família & Nome científico & Nome comum \\
\hline Asteraceae & Xanthium strumarium & Carrapichão \\
Asteraceae & Bidens pilosa & Picão-preto \\
Commelinaceae & Commelina benghalensis & Trapoeraba \\
Convolvulaceae & Ipomea purpurea & Corda-de-viola \\
Cyperaceae & Cyperus ferax & Tiririca \\
Euphorbiaceae & Ephorbia heterophyla & Leiteiro \\
Hypoxidaceae & Hypoxis decumbens & Falsa ciperacea \\
Malvaceae & Sida rhombifolia & Guanxuma \\
Poaceae & Digitaria sanguinalis & Milhã \\
Poaceae & Urochloa plantaginea & Papuã \\
\hline
\end{tabular}



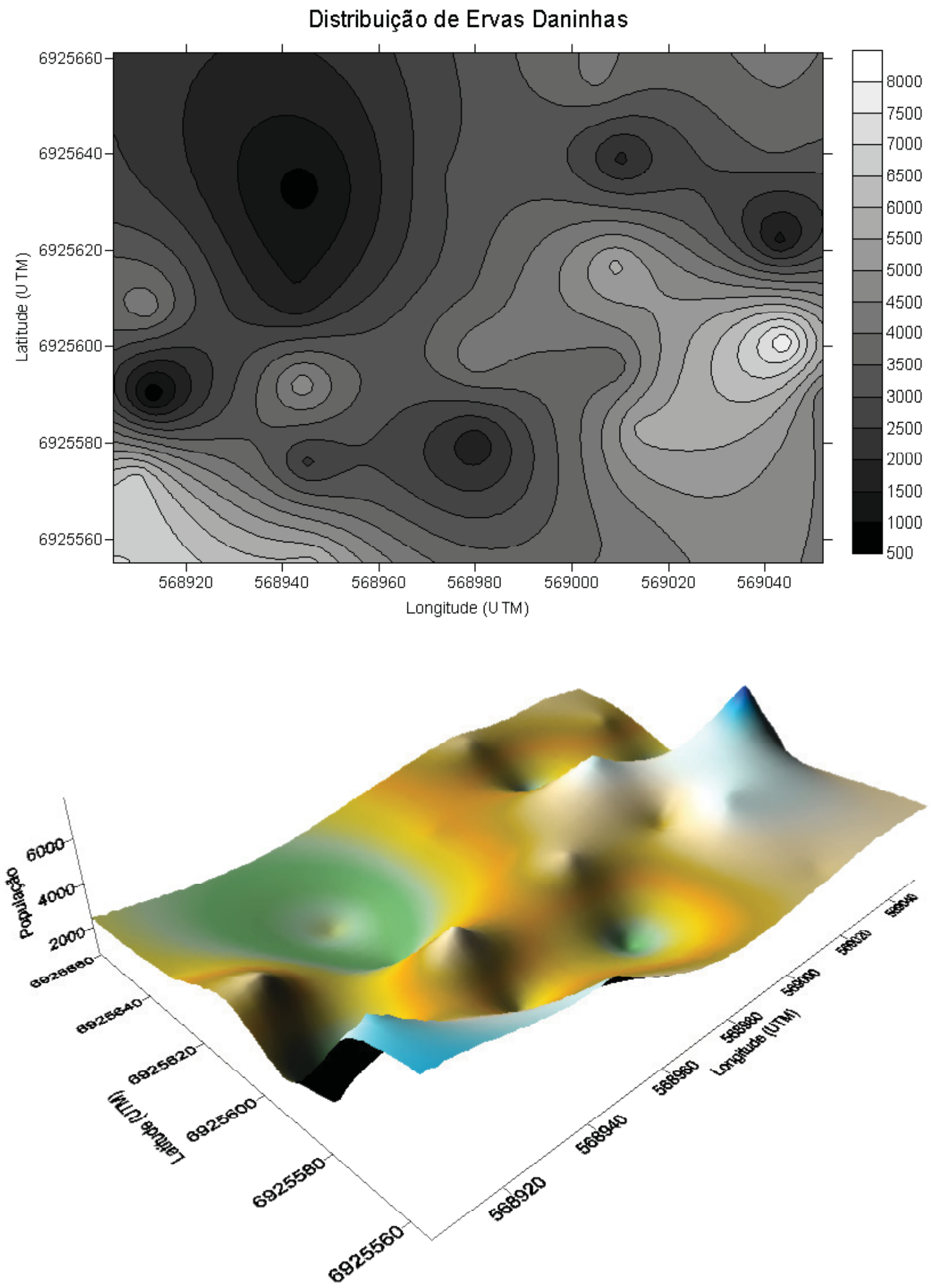

FIGURA 1: Distribuição espacial da infestação potencial de ervas daninhas em área de monocultivo de feijão. Áreas de infestação são representadas por pontos claros no gráfico de contorno e picos no gráfico de superfície. CAV/ UDESC - Lages/SC - 2008. 
Na Figura 2 são apresentados os mapas de infestação de monocotiledôneas na área nas formas de contorno e superfície. As populações de plantas pertencentes a esta classe foram bastante expressivas chegando a 3600 plantas $\mathrm{m}^{-2}$ em pontos dispersos na área (áreas claras e picos), e não sendo inferiores a 517 plantas $\mathrm{m}^{-2}$ (áreas escuras e vales).

Os pontos de menores populações são coincidentes para as duas classes taxonômicas (Figuras 2 e 3). Estes pontos são também áreas de cotas altimétricas mais baixas, onde ocorre acúmulo de água com frequência, interferindo tanto na manutenção do banco de sementes como no ciclo das plantas ali instaladas.

As altas populações de ervas daninhas encontradas na área em estudo podem estar correlacionadas com o método de preparo convencional do solo utilizado na área. A movimentação do solo, segundo Almeida (1981), favorece o desenvolvimento de infestação de plantas daninhas, tendo sido encontrados pelo mesmo autor, aumentos populacionais da ordem de $213 \%$ em relação ao não revolvimento do solo.

Muitas das plantas observadas pertencem à classe das plantas $\mathrm{C}_{4}$, o que agrava ainda mais a situação da cultura alvo em função do melhor aproveitamento por parte destas da água e luz presentes no ambiente. O feijão é uma planta $\mathrm{C}_{3}$ que tem seu desenvolvimento pleno em temperaturas amenas (em torno de $21^{\circ} \mathrm{C}$ ) e apresenta ponto de compensação luminoso de 150 a $250 \mathrm{~J}^{-\mathrm{m}^{-2} \mathrm{~s}^{-1}}$ (Laing et al., 1983), considerados valores relativamente baixos (Lopes, 1988). Durante a safra do feijão (verão), a ocorrência de alta temperatura e intensa radiação solar favorece o desenvolvimento das ervas daninhas em detrimento do feijão, podendo-se iniciar o seu controle mais cedo, principalmente nos pontos onde se verifica altas populações potenciais.

Dentro da classe das monocotiledôneas a espécie Urochloa plantaginea destaca-se pela população total encontrada, com uma média de 1227 plantas $\mathrm{m}^{-2}$. Entre as dicotiledôneas as maiores populações foram encontradas na espécie Xanthium strumarium, com média de população de 1357 plantas $\mathrm{m}^{-2}$. Os mapas de distribuição destas espécies são apresentados nas Figuras 4 e 5.

A distribuição da população de Urochloa plantaginea (Figura 4) demonstra-se muito similar à distribuição das plantas da classe das monocotiledôneas (Figura 2), sendo esta espécie a principal componente da referida classe de plantas.

Comportamento parecido apresentou a distribuição de Xanthium strumarium, com populações máximas de 3900 plantas $\mathrm{m}^{-2}$ (Figura 5).

O mapeamento da infestação, com auxilio da técnica de georreferenciamento mostrou-se uma ferramenta útil para predição do banco de sementes das plantas daninhas, podendo ser utilizado na tomada de decisão sobre métodos mais precisos de aplicação de herbicidas, reduzindo custos e poluição ambiental e maximizando a eficiência do controle de ervas daninhas.

Algumas espécies possuem alta densidade populacional na área, constituindo importante problema por competirem por recursos do ambiente com o feijão, desfavorecendo seu desenvolvimento e consequentemente a produção de grãos. 

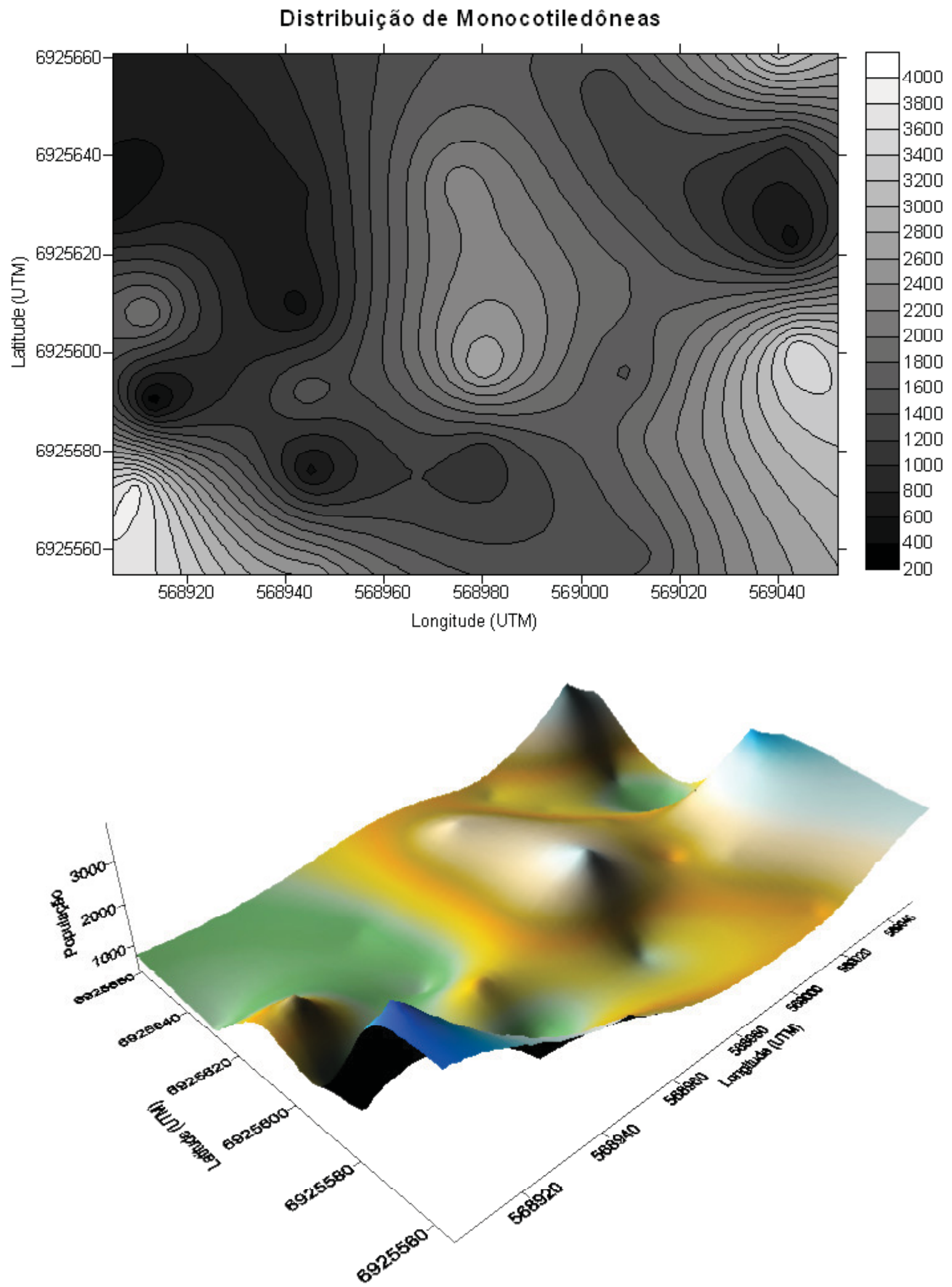

FIGURA 2: Distribuição espacial da infestação potencial de monocotiledôneas em área de monocultivo de feijão. Áreas de infestação são representadas por pontos claros no gráfico de contorno e picos no gráfico de superfície. CAV/UDESC - Lages/SC - 2008. 


\section{Distribuição de Dicotilêdoneas}
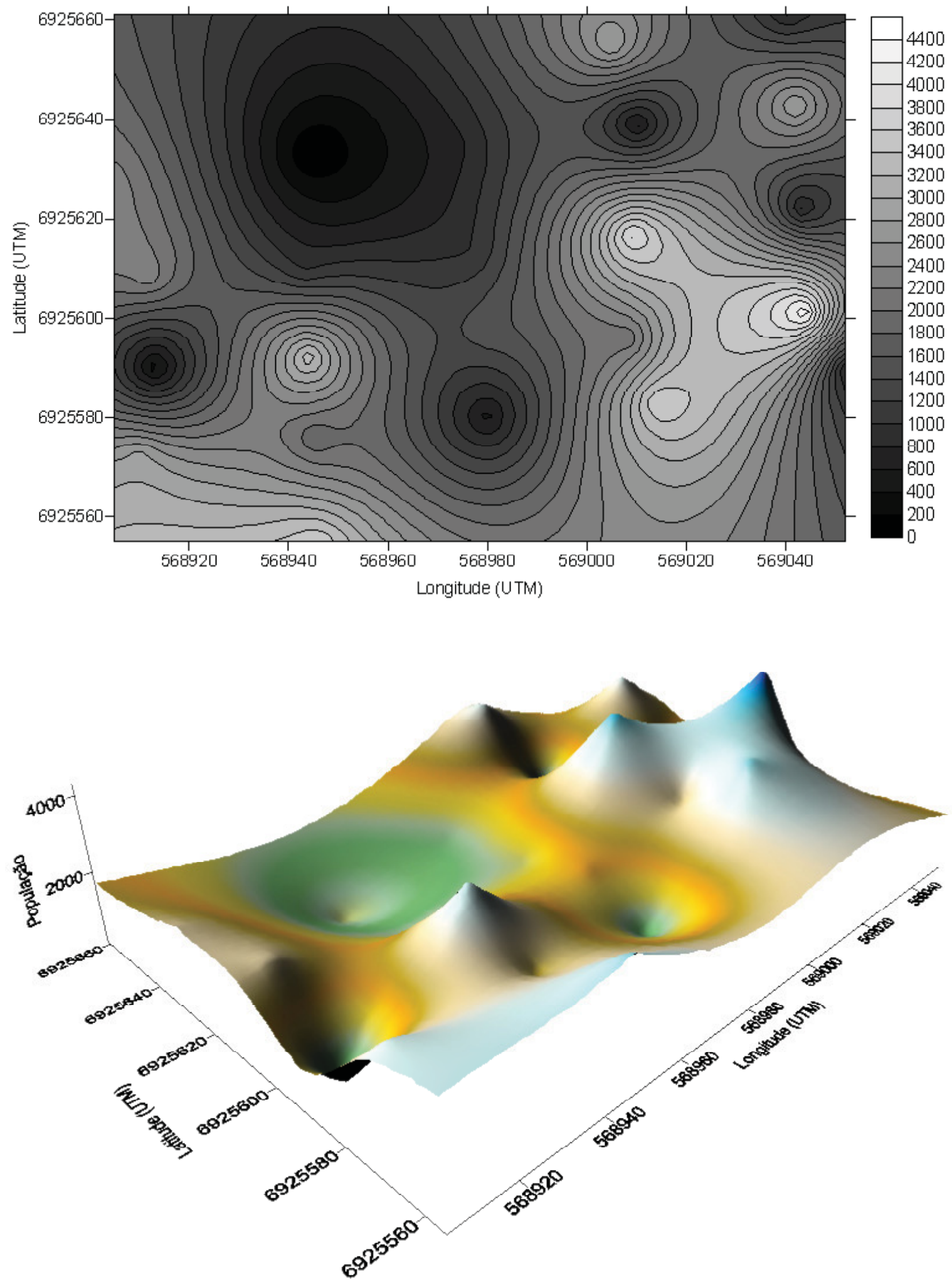

FIGURA 3: Distribuição espacial da infestação potencial de dicotiledôneas em área de monocultivo de feijão. Áreas de infestação são representadas por pontos claros no gráfico de contorno e picos no gráfico de superfície. CAV/UDESC - Lages/SC - 2008. 

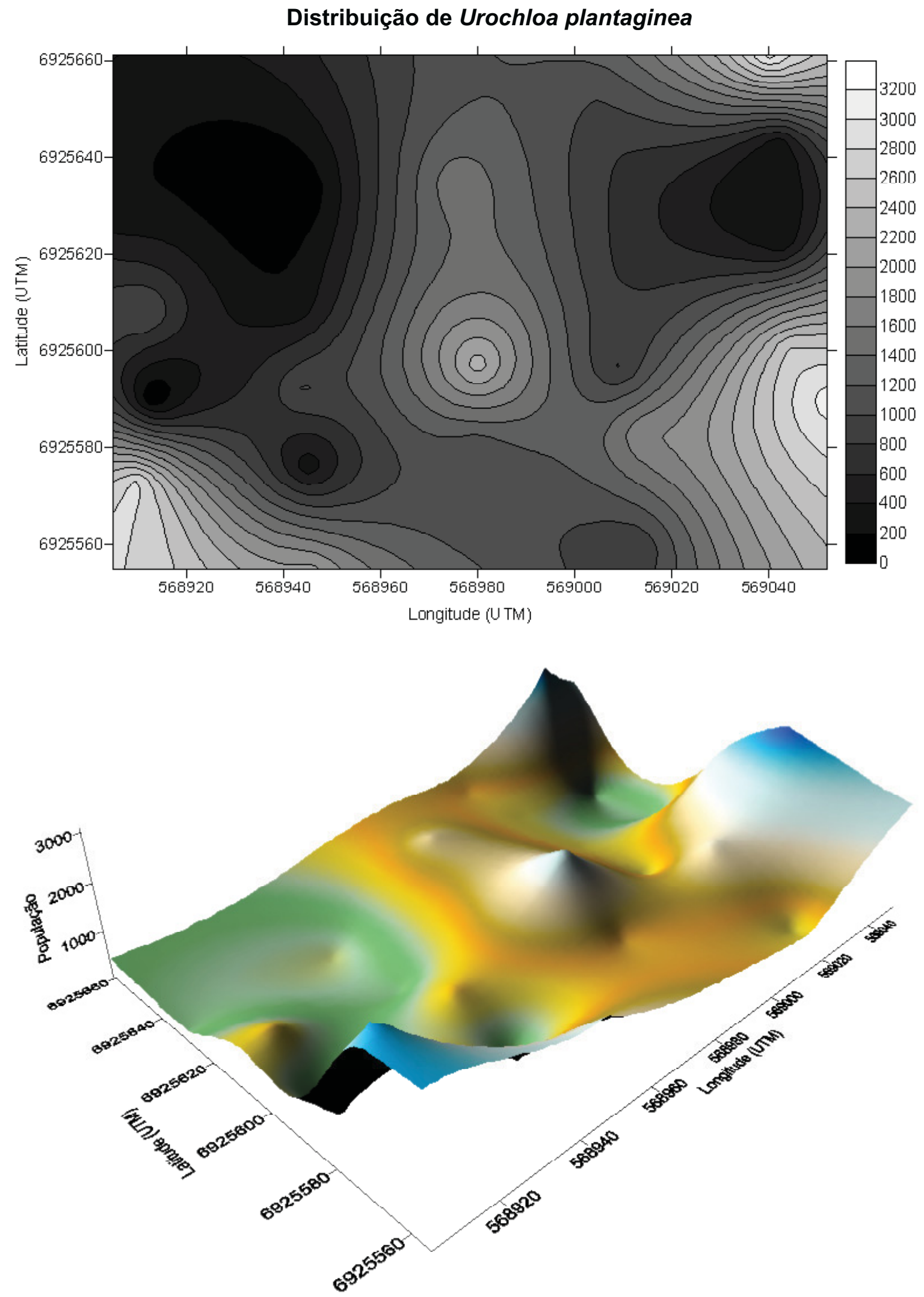

FIGURA 4: Distribuição espacial da infestação potencial de Urochloa plantaginea em área de monocultivo de feijão. Áreas de infestação representadas por pontos claros no gráfico de contorno e picos no gráfico de superfície. CAV/UDESC - Lages/SC - 2008. 


\section{Distribuição de Xanthium strmarium}
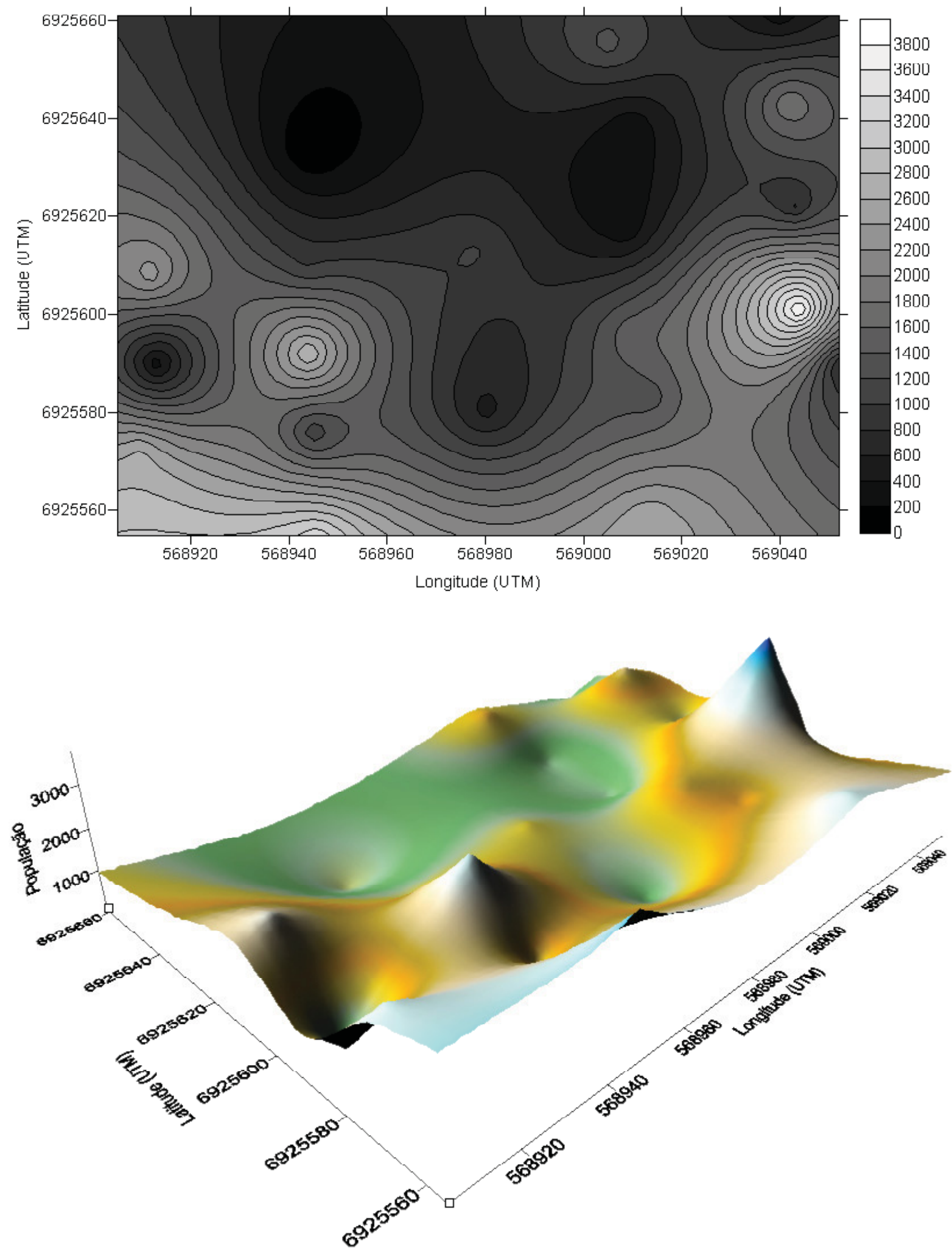

FIGURA 5: Distribuição espacial da infestação potencial de Xanthium strumarium em área de monocultivo de feijão. Áreas de infestação são representadas por pontos claros no gráfico de contorno e picos no gráfico de superfície. CAV/UDESC - Lages/SC 2008. 


\section{Referências}

Almeida, F. S. 1981. Controle de ervas. In: IAPAR (Ed.). Plantio direto no estado do Paraná. IAPAR, Londrina, Brasil, p.101-138. Carmona, R. 1992. Problemática e manejo de bancos de sementes de invasoras em solos agrícolas. Planta Daninha, 10: 5-16.

Braverman, M. P.; Lavy, T. L.; Barnes, C. J. 1986. Degradation and bioactivity of metolahlor in the soil. Weed Science, 34 (3): 479484.

Burgard, D. J.; Koskinen, W. C.; Dowdy, R. H.; Cheng, H. H. 1993. Metolachlor distribution in a sandy soil under irrigated potato production. Weed Science, 41 (4): 648-655.

Christensen, S.; Walter, A. M.; Heisel, T. 1999. The patch treatment of weeds in cereals. Proceedings of Brighton Conference on Weeds, Brighton, UK, p. 591-600.

Clay, S.; Johnson, G. 1999. Scouting for weeds. Site-specific management guidelines. Disponível em $<\mathrm{http}$ ://ppi-far.org/ssmg $>$. Acesso em 15 de outubro de 2008.

Embrapa. 1999. Sistema brasileiro de classificação de solos. Centro Nacional de Pesquisa de Solos, Brasília, Brasil, 412pp.

Cobucci, T. 1996. Avaliação agronômica dos herbicidas fomesafen e bentazon e efeito de seus resíduos no ambiente, no sistema irrigado feijão-milho. Tese de Doutorado, Universidade Federal de Viçosa, Brasil, 106pp.

Harper, S. S. 1994. Sorption-desorption and herbicide behavior in soil. Review of Weed Science, 6 (1): 207-225.

Imai, N. N.; Vicente, J.; Lima, D. L.; Tashibana, V. M.; Silva, E. A.; Voll, E.; Oliveira, H. E. S. 2003. Análise comparativa da interpolação por krigagem ordinária e krigagem por indicação no caso de ervas daninhas em cultura de soja. Anais do XXI Congresso Brasileiro de Cartografia, Belo Horizonte, Brasil, CD-Rom.

Keller, K. E.; Weber, J. B.; Cassel, D. K.; Wollum, A. C.; Miller, C. T. 1998. Temporal distribution of $14 \mathrm{C}$ in soil water from field lysimeters treated with 14 Cmetolachlor. Soil Science, 11: 872882 .

Kissmann, K. G. 1997. Plantas infestantes e nocivas. $2^{\mathrm{a}}$ ed. Tomo II. BASF Brasileira, São Paulo, Brasil, 824pp.

Kissmann, K. G. 2000. Plantas infestantes e nocivas. $2^{\mathrm{a}}$ ed. Tomo III. BASF Brasileira, São Paulo, Brasil, 722pp.
Kissmann, K. G.; Groth, D. 1999. Plantas infestantes e nocivas. $2^{\text {a }}$ ed. Tomo II. BASF Brasileira, São Paulo, Brasil, 978pp.

Laing, D. R.; Kretchmer, P. J.; Zuluaga, S.; Jones, P. G. 1983. Field bean (Phaseolus vulgaris). In: Smith, W. H. \& Yashida, S. (Eds). Potencial productivity of field crops under different environments. IRRI, Los Baños, Philippines, p.227-248.

Lamb, D. W.; Brown, R. B. 2001. Remote-sensing and mapping of weeds in crops. Journal of Agricultural Engineering Research, 78: 117-25.

Lopes, N. F. 1988. Adaptabilidade fisiológica ao consórcio. In: Zimermann, M. J. O.; Rocha, M. \& Yamada, T. (Eds). Cultura do feijoeiro: Fatores que afetam a produtividade. POTAFÓS, Piracicaba, Brasil, p.375-396.

Monquero, P. A.; Amaral, L. R.; Binha, D. P.; Silva, P. V.; Silva, A. C. 2008. Mapas de infestação de plantas daninhas em diferentes sistemas de colheita da cana-de-açúcar. Planta Daninha, 26: 4755.

Rodrigues, B. N.; Almeida, F. R. 1998. Guia de herbicidas. $4^{\text {a }}$ ed. Edição dos Autores, Londrina, Brasil, 648pp.

Roza, D. 2000 Novidade no campo: Geotecnologias renovam a agricultura. Revista InfoGEO, 11. Disponível em $<$ http://www. infogeo.com.br/Revista/materia_11.htm $>$. Acesso em 22 de março de 2009.

Salvador, A.; Antuniassi, U. R. 2002. Métodos de mapeamento da distribuição espacial da infestação por plantas daninhas em sistemas de agricultura de precisão. Anais do II Simpósio Internacional de Agricultura de Precisão, Viçosa, Brasil, p.1-4.

Stafford, J. V.; Miller, P. C. H. 1996. Spatially variable treatment of weed patches. Proceedings of International Conference on Precision Agriculture, Madison, USA, p.465-474.

Voll, E.; Gazziero, D. L. P.; Quina, E.; Krzyzanowski, F. C. 1997. Embebição e germinação de sementes de capim-marmelada. Revista Brasileira de Sementes, 19 (1): 58-61.

Weber, J. B.; Strek, H. J.; Sartori, J. L. 1993 Mobility of fomesafen and atrazine in soil columns under satured and unsaturede flow conditions. Pesticide Science, 39 (1): 39-46.

Zablotowicz, R. M.; Locke, M. A.; Gaston, L. A.; Bryson, C. T. 2000. Interactions of tillage and soil depth on fluometuron degradation in a Dundee silt loam soil. Soil and Tillage Research, 57 (2): 61-68. 